\title{
Factors determining the concentration and chemical composition of particulate matter in the air of selected service facilities
}

\author{
Patrycja Rogula-Kopiec. ${ }^{1, *}$, Józef Pastuszka², Barbara Mathews ${ }^{1}$, Kamila Widziewicz ${ }^{l}$ \\ ${ }^{1}$ Institute of Environmental Engineering, Polish Academy of Sciences, M. Skłodowskiej-Curie St. 34, \\ 41-819 \\ Zabrze, \\ Poland \\ ${ }^{2}$ Department of Air Protection, Silesian University of Technology, Center of New Technologies, \\ Konarskiego St. 22B, 44-100 Gliwice, Poland
}

\begin{abstract}
The link between increased morbidity and mortality and increasing concentrations of particulate matter (PM) resulted in great attention being paid to the presence and physicochemical properties of PM in closed rooms, where people spends most of their time. The least recognized group of such indoor environments are small service facilities. The aim of this study was to identify factors which determine the concentration, chemical composition and sources of PM in the air of different service facilities: restaurant kitchen, printing office and beauty salon. The average PM concentration measured in the kitchen was 5-fold $\left(\mathrm{PM}_{4}\right.$, particle fraction $\left.\geq 4 \mu \mathrm{m}\right)$ and 5.3-fold (TSP, total PM) greater than the average concentration of these PM fractions over the same period. During the same measurement period in the printing office and in the beauty salon, the mean PM concentration was 10- and 4-fold $\left(\mathrm{PM}_{4}\right)$ and 8and 3-fold (TSP) respectively greater than the mean concentration of these PM fractions in outdoor air. In both facilities the main source of PM macro-components, especially organic carbon, were chemicals, which are normally used in such places - solvents, varnishes, paints, etc. The influence of some metals inflow from the outdoor air into indoor environment of those facilities was also recognized.
\end{abstract}

\section{Introduction}

The quality of air inside various types of rooms, regardless the time people spend indoors, depends primarily on the activity of indoor occupants, the type of this activity and the effectiveness of ventilation. In kitchen facilities where meals are prepared (cooking, frying) and the coal stove or fireplace is being used, the quality of indoor air is generally worse compared to outdoor one. This mostly applies to particulate matter (PM) air pollution, and especially to its fine particles [1-5].

Fine atmospheric particles are free to migrate inside the buildings, which makes their indoor concentration similar (or higher) compared to the outdoor one. Such tendency may

*Corresponding author: patrycja.rogula-kopiec@ipis.zabrze.pl 
or may not occur depending on the presence and effectiveness of internal sources of PM and other pollutants emission (i.e. various gases adsorbed on PM or reacting with each other and/or other PM components), the way in which the room is ventilated (preventing or favoring PM accumulation inside), or the effectiveness of ventilation system [6-10].

Due to the nuisance associated with emission of various air pollutants at workplace and the need to estimate workers exposure to these pollutants the occupational levels of PM during the working hours is currently being monitored at various industrial facilities. Nevertheless, there are many facilities where, despite the fact of heavily contaminated indoor air, there are no legal requirements for the monitoring of pollutants concentrations in their interiors. This anticipated significant air pollution within facilities can be caused either by the building location (for example in highly contaminated region) or the presence of internal pollution sources and in some certain conditions such facilities can be subjected to the excessive accumulation of indoor pollutants. The need to assess the indoor air quality in such facilities is objectively justified when even one from the abovementioned factors occurs.

The Upper Silesian Agglomeration is one of Europe's most polluted region in terms of air quality. The concentrations of PM and PM-bound compounds in some cities of the Agglomeration are several times higher than in large cities of Western, Northern and Southern Europe [11-13]. In comparison to other Polish and European regions, Silesia Agglomeration is also one of the most industrialized and urbanized areas. Within the Upper Silesian Agglomeration, which consists of 14 cities with a total population exceeding 2 million people, more than $60 \%$ of employees work in the so-called services. Some of the service facilities which provides a particular service are a significant sources of internal pollutants emission. These are among others printing offices and beauty salons [13, 14]. In such places, due to the type of activity, high ambient concentrations of various organic pollutants can be expected.

Considering the presence of high concentrations of PM in the Silesia urban agglomeration and a relatively high concentrations of PM-bound carbon and some other components of PM $[15,16]$, it was reasonable to investigate the effects of the activities carried out in these facilities on the formation of PM and PM-bound carbonaceous matter, ions and selected metals.

\section{Methodology}

The study was performed in restaurant kitchen, printing office and beauty salon (Figure 1) located in Bytom (one among14 cities located in the Upper Silesian Agglomeration with an area of $69 \mathrm{~km}^{2}$ and 170 thousand inhabitants). All service facilities, chosen for this study are located within the same housing estate. There are no power plants, large industrial/manufacturing plants or any major communications arteries close to those facilities.

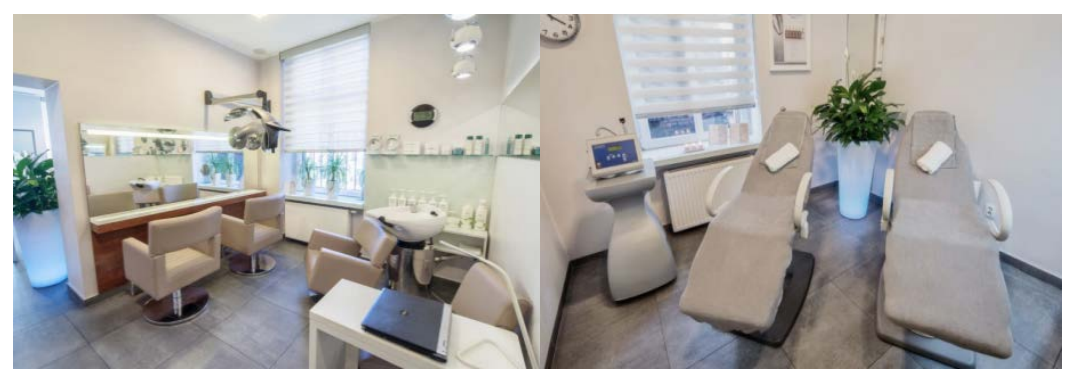




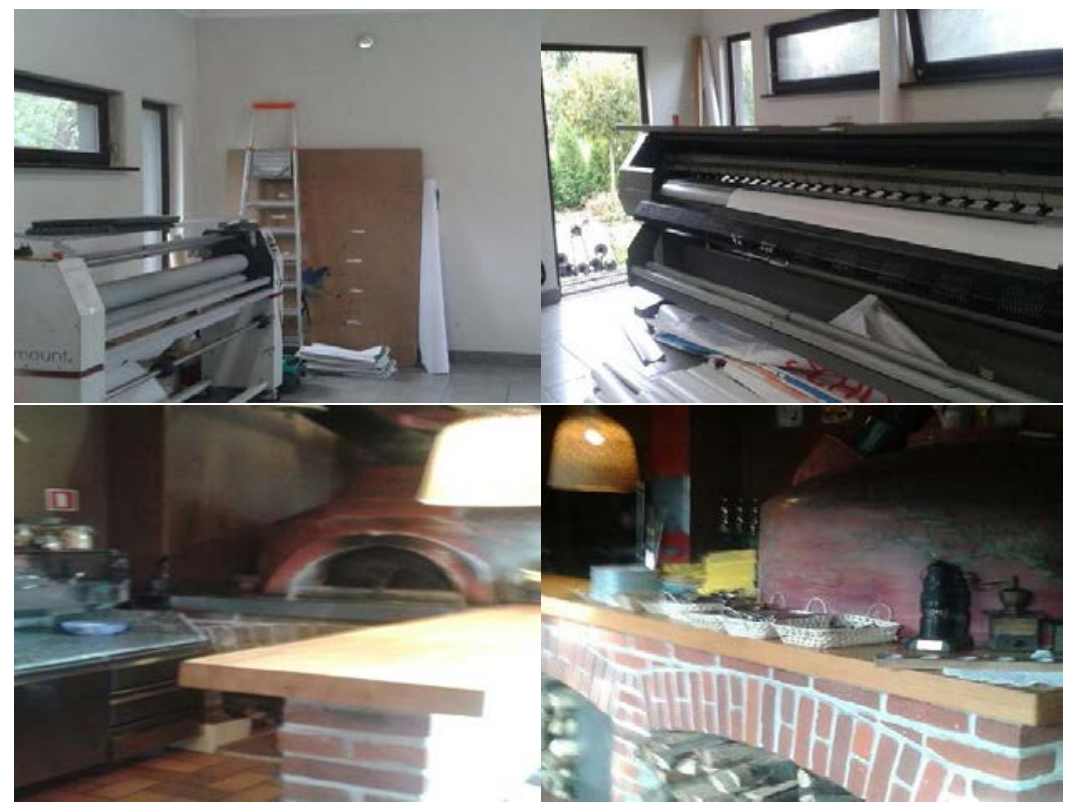

Fig. 1. Selected service facilities

Selected printing office provide printing services like large format printing on a variety types of paper and films, but also other services like thermal treatment (welding) the edges of the selected products (banners, posters). Sampling was conducted in a hall with an area of about $50 \mathrm{~m}^{2}$, which run printing, at a distance of about $3 \mathrm{~m}$ in a straight line from the printing machine. The sampling site was located in a new building, where customer office (about $15 \mathrm{~m}^{2}$ ), social room $\left(10 \mathrm{~m}^{2}\right)$ and a toilet are being placed. The building has a natural ventilation system and two large (PVC) windows on each wall. In the summer, when the measurements were carried out the door between the hall and the office together with the exit door (emergency exits from the hall) and windows were constantly opened. All printouts from the machine are hanging to dry in the open air inside the hall, at the time when the machine is kept on a standby, for example when cyclical printing areas are sprayed with the appropriate solvent.

The beauty salon is located in a residential building, adopted for service activities. Measurements were carried out in one among five rooms belonging to the salon (in each room a different kind of treatments is being run) - the office, where pedicure and manicure are performed. The room has an area of about $30 \mathrm{~m}^{2}$. The room is equipped with a seat for customers and a beauty table. Measurements were conducted at a distance of approximately $3 \mathrm{~m}$ from the table. The building is equipped with a gravity ventilation and PVC windows, most of which are closed, and the room is ventilated only after the working day is end (after 18.00). During work a beautician uses milling machine, nail-files, and a number of cosmetics containing hydrocarbons, alcohols, esters, phenols, and others. Nail coatings and gels are cured under UV lamp.

The restaurant is placed in a ground floor of a relatively new building (built in $2000 \mathrm{yr}$.) equipped with efficient mechanical ventilation. The restaurant kitchen in a separate room (area of about $40 \mathrm{~m}^{2}$ ) which is in contact with the restaurant hall. It is equipped with two electric stoves, two gas stoves and one wood-fired oven, which is designed for baking breads and pizzas. There are 6 people in the kitchen during the working hours. This is an example of a typical kitchen found in a relatively modern restaurants in Polish cities. In 
Bytom there are about 50 such objects, while in whole Silesia conurbation more than 1000 .

PM samples were collected in the period of 1-30 September 2016 in a 8-hour cycles, usually between 10.00-18.00, therefore during work hours. All measurements were performed by an identical set of two $\mathrm{PM}_{4}$ (particles with aerodynamic diameter not greater than $4 \mu \mathrm{m}$ ) and TSP (total suspended particles; aerodynamic diameter in the range $1 \mathrm{~nm}$ $100 \mu \mathrm{m})$ samplers (GilAir PLUS, Ekohigiena, Radom), located inside the facilities as well as in the outside. Altogether 40 samples of $\mathrm{PM}_{4}$ (20 indoor and 20 outdoor) and 40 samples of TSP (20 indoor and 20 outdoor) were collected in each facility.

Samples were collected on Whatman quartz filters (QMA, ø25 mm) (GE Medical Systems Poland, Life Sciences, Warsaw) using the GilAir Plus samplers (Sensidyne, St. Petersburg, FL). The PM mass was determined by gravimetric analyses using a microbalance (resolution of $1 \mu \mathrm{g}$ ) (Radwag; Radom, Poland) $[3,13,15,16]$. The contents of OC and EC in PM was determined using a thermal-optical analyzer Lab OC-EC Aerosol Analyzer (Sunset Laboratories Inc.; Portland, OR, USA) and the measurement procedure EUSAAR $[5,13,16]$; while the ions contents in the PM water extracts was analyzed using ion chromatography (Metrohm AG; Herisau, Switzerland) $[3,13,16]$.

Metal quantitative analysis was preceded by sample mineralization in a mixture of spectrally pure (Merck, Ultrapure) acids. Before mineralization, samples were flooded with $5 \mathrm{~mL}$ of nitric acid $\mathrm{HNO}_{3}(65 \%), 1 \mathrm{~mL}$ of hydrofluoric $\mathrm{HF}(40 \%)$, and $1 \mathrm{~mL}$ of perchloric acid $\mathrm{HClO}_{4}(70 \%)$. Mineralization was carried out in a microwave digestion system, Multiwave 3000 from Anton Paar, in sealed polytetrafluoroethylene PTFE vessels under pressure (mineralization furnace parameters: a pressure rise of $0.3 \mathrm{bar} / \mathrm{s} ; 240^{\circ} \mathrm{C}$; pressure 60 bar; mineralization time $50 \mathrm{~min}$ ). PM-bound trace metal concentrations were determined by inductively coupled plasma mass spectrometry (ICP-MS, Perkin Elmer DRC-e 6100) equipped with a dynamic reaction cell. The operating conditions are listed below: ICP RF power: $1125 \mathrm{~W}$; nebulizer gas flow rate: $0.78-0.83 \mathrm{~L} / \mathrm{min}$; auxiliary gas flow: $1.15 \mathrm{~L} / \mathrm{min}$; plasma gas flow: $15 \mathrm{~L} / \mathrm{min}$; sample flow rate: $1 \mathrm{~mL} / \mathrm{min}$. Certified multi-elemental standard stock solutions Periodic table mix 1 and Transition metal mix 2 (Fluka) were used as calibration solutions. The analytical method was validated by determination of selected elements content in the Standard Reference Material, SRM 1648a, (urban particulate matter), obtained from the National Institute of Standard and Technology (NIST). The obtained results were corrected by the mean concentrations of metals in blank samples (non-exposed filters). Recovery rates were in the range: 83\% $(\mathrm{Cd})-127 \%(\mathrm{Cr})$.

\section{Results and discussion}

In two among three facilities (restaurant kitchen and beauty salon) the concentrations of $\mathrm{PM}_{4}$ were much higher compared to atmospheric air $(\mathrm{I} / \mathrm{O}>5)$. These dependences are shown in Table 1. This is a rule and regardless how high concentrations of outdoor $\mathrm{PM}_{4}$ occur in the following measurement days, the indoor concentrations of those were each time higher.

The effect of fine particles $\left(\mathrm{PM}_{4}\right)$ accumulation inside the beauty salon and restaurant kitchen was significant. This does not apply to $\mathrm{PM}_{4}$ in a printing office, which indoor concentration was on average even slightly lower than in atmospheric air. In all facilities the TSP concentrations were also slightly lower compared to the outdoor ones $(\mathrm{I} / \mathrm{O}<1)$. A similar effect of PM accumulation inside the buildings was observed earlier in a lecture rooms in Gliwice and Warsaw cities [16,17]. In case of lecture rooms, where there were no internal sources of fine PM or PM precursors, this phenomenon was fully explained by insufficiently effective air exchange in the examined rooms. In considered facilities in addition to insufficiently effective ventilation, one of the reason for the high indoor PM concentrations is the emission of PM and/or its precursors from the internal emission 
sources. This is evident when analyzing the I/O (Inside/Outside) ratios of PM (Table 1), and selected PM components (Table 2). 
Table 1. Mean ( \pm standard deviation) of $\mathrm{PM}_{4}$ and TSP concentrations inside (I) and outside (O) the tested facilities and their $\operatorname{ratios}(\mathrm{I} / \mathrm{O})$.

\begin{tabular}{|c|c|c|c|c|c|}
\hline \multicolumn{2}{|c|}{$\mathbf{P M}_{4}$} & \multicolumn{2}{|c|}{ TSP } & \multirow{2}{*}{$\begin{array}{c}\mathrm{PM}_{4} \\
\mathrm{I} / \mathrm{O}\end{array}$} & \multirow{2}{*}{$\begin{array}{l}\text { TSP } \\
\text { I/O }\end{array}$} \\
\hline (O) & (I) & (O) & (I) & & \\
\hline \multicolumn{6}{|c|}{ RESTAURANT KITCHEN $n=80, \mathrm{PM}_{4}-20(\mathrm{I})$ and $20(0), \mathrm{TSP}-20(\mathrm{I})$ and $20(0)$} \\
\hline $11.28 \pm 4.96$ & $96.57 \pm 60.37$ & $155.83 \pm 301.25$ & $153.1 \pm 217.4$ & 8.6 & 1.0 \\
\hline \multicolumn{6}{|c|}{ PRINTING OFFICE n=80, PM4 $-20(I)$ and $20(0)$, TSP-20(I) and 20(O) } \\
\hline $73.31 \pm 204.44$ & $58.46 \pm 27.69$ & $169.27 \pm 328.36$ & $87.55 \pm 46.82$ & 0.8 & 0.5 \\
\hline \multicolumn{6}{|c|}{ BEAUTY SALON n=80, PM $4-20(I)$ and 20(O), TSP-20(I) and 20(O) } \\
\hline $11.11 \pm 4.85$ & $62.66 \pm 63.41$ & $169.27 \pm 328.36$ & $98.48 \pm 108.65$ & 5.6 & 0.6 \\
\hline
\end{tabular}

Table 2. The average (I/O) concentration ratios of PM components

\begin{tabular}{|c|c|c|c|c|c|c|}
\hline \multirow[t]{2}{*}{ Component } & \multicolumn{2}{|c|}{ Beauty salon } & \multicolumn{2}{|c|}{ Restaurant kitchen } & \multicolumn{2}{|c|}{ Printing office } \\
\hline & $\mathrm{PM}_{4}(\mathrm{I} / \mathrm{O})$ & $\operatorname{TSP}(\mathbf{I} / 0)$ & $\mathrm{PM}_{4}(\mathrm{I} / \mathrm{O})$ & $\operatorname{TSP}(\mathrm{I} / \mathrm{O})$ & $\mathrm{PM}_{4}(\mathrm{I} / \mathrm{O})$ & $\operatorname{TSP}(\mathrm{I} / 0)$ \\
\hline OC & 6.1 & 2.4 & 5.1 & 3.1 & 1.2 & 1.4 \\
\hline EC & 3.3 & 1.0 & 5.2 & 1.5 & 4.1 & 2.1 \\
\hline Mn & 3.2 & 0.5 & 7.5 & 0.9 & 0.3 & 0.3 \\
\hline Co & 1.4 & 1 & 1.1 & 0.9 & 0.4 & 0.6 \\
\hline $\mathbf{N i}$ & 0.2 & 0.3 & 0.3 & 0.3 & 0.2 & 0.1 \\
\hline $\mathrm{Cu}$ & 1.9 & 0.7 & 1.7 & 1.1 & 0.7 & 0.4 \\
\hline Zn & 2 & 1.1 & 2.3 & 1.9 & 0.3 & 0.2 \\
\hline Cd & 1.2 & 0.6 & 1.4 & 0.7 & 0.8 & 1 \\
\hline $\mathbf{P b}$ & 1.8 & 0.4 & 2.5 & 0.5 & 0.7 & 0.2 \\
\hline $\mathrm{Cr}$ & 2 & 0.5 & 2.6 & 0.4 & 0.3 & 0.3 \\
\hline $\mathbf{N a}^{+}$ & 10.8 & 1 & 26.1 & 1.6 & 0.4 & 0.3 \\
\hline $\mathbf{N H}_{4}{ }^{+}$ & 4.6 & 6.8 & 19.4 & 4.4 & 2.2 & 1.1 \\
\hline $\mathbf{K}^{+}$ & 37.1 & 6.8 & 135.8 & 4.4 & 49.1 & 2.3 \\
\hline
\end{tabular}




\begin{tabular}{|c|c|c|c|c|c|c|}
\hline $\mathbf{C a}^{2+}$ & 1 & 2 & 11.6 & 28.8 & 49.1 & 2.3 \\
\hline $\mathbf{M g}^{2+}$ & 25.3 & 0.7 & 23.9 & 3.6 & 3.3 & 10.4 \\
\hline $\mathbf{F}^{-}$ & 10.1 & 0.9 & 20.1 & 1.5 & 29.4 & 2.1 \\
\hline $\mathbf{C l}^{-}$ & 7.4 & 0.6 & 2.7 & 0.6 & 2.1 & 1 \\
\hline $\mathbf{N O}_{3}{ }^{-}$ & 1.1 & 0.7 & 2 & 1.1 & 0.4 & 0.8 \\
\hline $\mathbf{P O}_{4}{ }^{3-}$ & 10.2 & 1 & 20.9 & 2.1 & 1.2 & 1.5 \\
\hline $\mathbf{S O}_{4}{ }^{2-}$ & 9.1 & 1 & 25.7 & 2.3 & 2 & 1.4 \\
\hline
\end{tabular}

Significantly higher levels of PM-bound OC and EC concentrations and some watersoluble ions inside the considered facilities compared to the outside ones 1 . had be probably due to indoor emissions; 2. affect the concentration of the measured components in the tested rooms. This is especially evident in case of OC concentrations in the beauty salon and restaurant kitchen; and less obvious is the printing office (Table 2). It could be therefore concluded that a decisive influence of PM-bound carbon emissions (most likely volatile organic compounds) on the formation of $\mathrm{OC}$ concentrations has been noted during cosmetic treatments in a beauty salon; during cooking and meal preparation inside restaurant kitchen (this also includes the emission of the primary organic matter) and printing works inside the printing office. A significant differences were found between the indoor and outdoor concentrations regarding both the PM-bound OCs concentrations and its mass share in the PM (Figure 2). Both parameters remain at a very high level in all facilities no matter if $\mathrm{OC}$ was associated with fine or coarse particles. Both in the printing office and in the restaurant kitchen the concentration and the mass shares of PM-bound EC are higher than in atmospheric air, which is likely to be influenced by various processes (including combustion) carried out in both facilities. These processes were also associated with generally higher concentrations of $\mathrm{PM}_{4}$-bound water-soluble ions, i.e. $\mathrm{K}^{+}, \mathrm{Ca}^{2+}, \mathrm{NH}_{4}^{+}$, $\mathrm{Mg}^{2+}, \mathrm{F}-$ and $\mathrm{SO}_{4}{ }^{2-}$ in these facilities with respect to their concentrations in atmospheric air (Table 2).The concentrations of $\mathrm{PM}_{4}$-bound ions were also much higher inside the beauty salon than in the outside. In the beauty salon and in the restaurant kitchen the service activities also influence the differences in the concentrations of $\mathrm{Na}^{+}$and $\mathrm{NO}_{3}{ }^{-}$between indoor and outdoor environment. The elevated concentrations of some ions inside facilities (like for example $\mathrm{SO}_{4}{ }^{2-}, \mathrm{NH}_{4}{ }^{+}$and $\mathrm{NO}_{3}{ }^{-}$) in relation to their outdoor levels can be caused by two phenomena: first of all, due to the occupant activity, and secondly due to the emission of gaseous precursors of those components, like $\mathrm{SO}_{x}, \mathrm{NO}_{\mathrm{x}}$ and $\mathrm{NH}_{3}[16,17]$. However, independently of the presence of the indoor emission sources, it can be expected that the $\mathrm{SO}_{4}{ }^{2-}, \mathrm{NH}_{4}+$ and $\mathrm{NO}_{3}{ }^{-}$gaseous precursors that migrate into the facilities along with the atmospheric air (or/and those emitted inside), under stable temperature conditions, high humidity and limited movement of the air masses (i.e., the conditions prevailing in all enclosed spaces where people actually live), will soon be transformed/reacted more readily than in atmospheric air, thus forming a primary, next to carbon matter, fine PM component - the secondary inorganic aerosol. It is worth to note that not only in case of $\mathrm{PM}_{4}$ fraction the water-soluble ions were significantly higher inside the facilities; this also applies to TSP. The highest concentration of TSP-bound $\mathrm{Ca}^{2+}$ occurred in the restaurant kitchen, the TSP-bound $\mathrm{NH}_{4}{ }^{+}$and $\mathrm{K}^{+}$in the restaurant and beauty salon interiors while in case of TSPbound $\mathrm{Mg}^{2+}$ in the printing office (Table 2). In the case of $\mathrm{PM}_{4}$, the concentrations of some elements were also definitely higher inside the facilities than in the atmospheric air. This 
applies especially to $\mathrm{Mn}, \mathrm{Co}, \mathrm{Ni}, \mathrm{Cu}, \mathrm{Zn}, \mathrm{Cd}, \mathrm{Pb}, \mathrm{Cr}$ (Table 2). These elevated concentrations, aren't however correlated with the higher shares of these metals in the $\mathrm{PM}_{4}$ mass (Figure 2). In general, the activities carried out in the investigated facilities did not affect the contents of heavy metals and in case of beauty salons also the concentrations of ions derived from the water-soluble TSP compounds. 


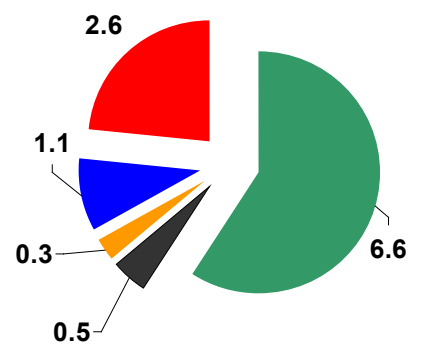

12.0

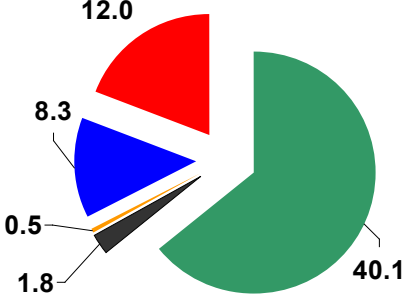

PM4_Outdoor

$\square \mathrm{OC}$

aC

sum of metals

asum of ions

n unidentified matter

\section{PM4_Indoor}

- OC

$\square \mathrm{EC}$

a sum of metals

a sum of ions

—unidentified matter

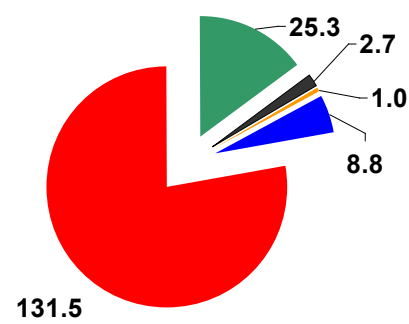

21.2

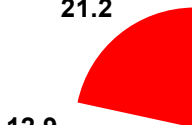

12.9

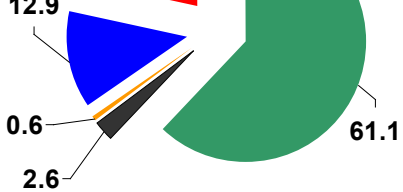

TSP_Outdoor

-OC

$\square \mathrm{EC}$

w sum of metals

घum of ions

—unidentified matter

TSP_Indoor
OC
EC
sum of metals
sum of ions
unidentified matter

a) beauty salon 

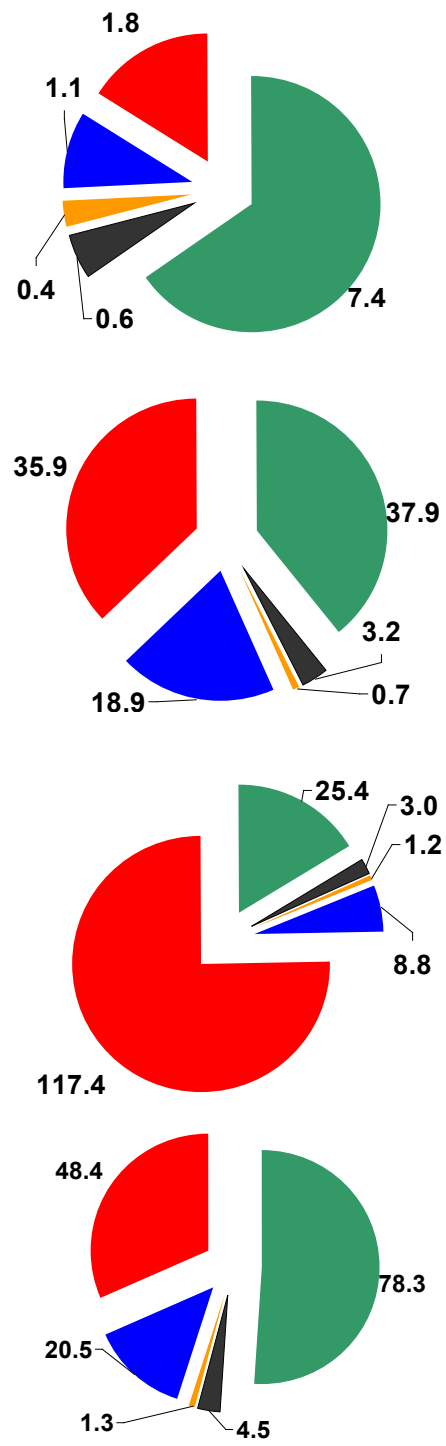

b) restaurant kitchen
PM4_Outdoor

aC

口EC

sum of metals

a sum of ions

— unidentified matter

PM4_Indoor

口OC

$\square \mathrm{EC}$

sum of metals

num of ions

— unidentified matter

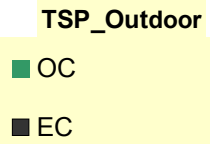

sum of metals

aum of ions

- unidentified matter

$$
\text { TSP_Indoor }
$$

口 OC

口EC

sum of metals

w sum of ions

—unidentified matter 

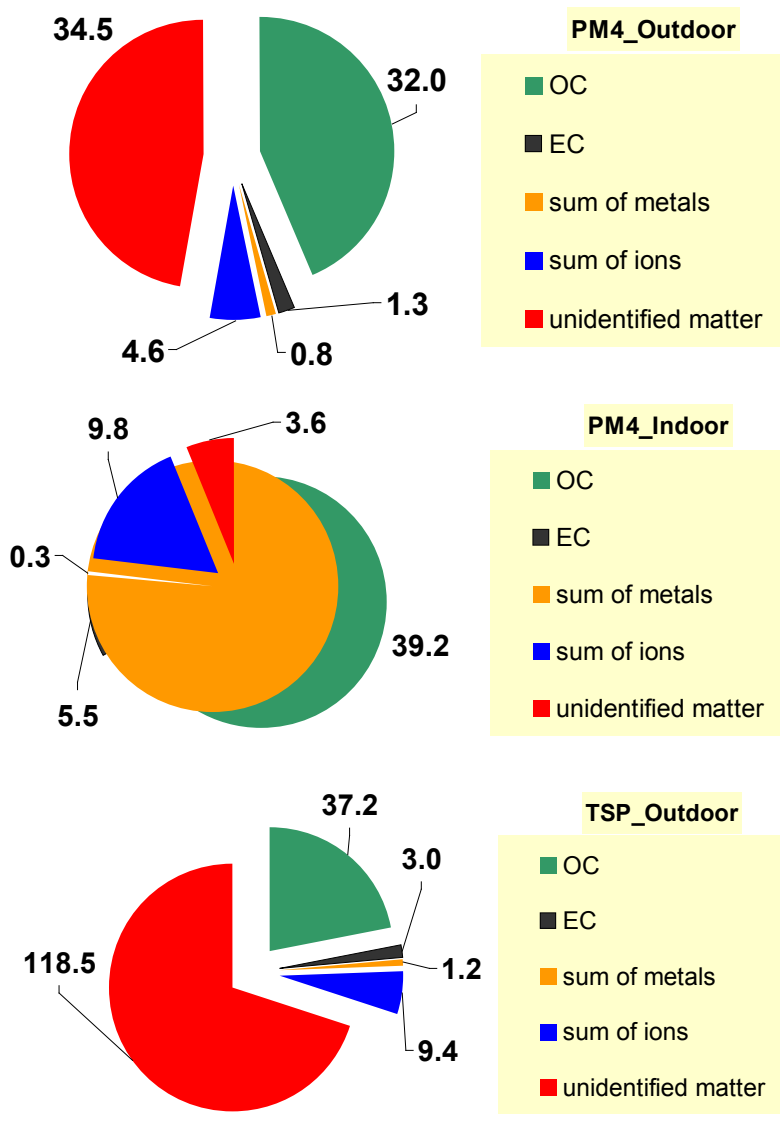

TSP_Outdoor
OC
EC
sum of metals
sum of ions
unidentified matter
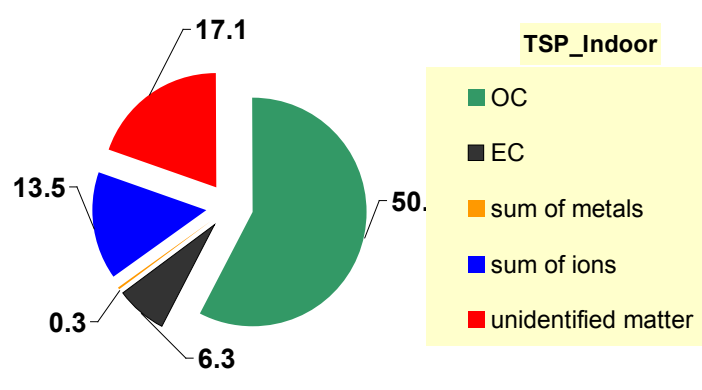

c) printing office

Fig. 2. The average chemical composition of PM4 and TSP in selected service facilities and in atmospheric air during the measurement period (the numbers on the labels indicate the concentrations of selected PM components in $\mu \mathrm{g} / \mathrm{m}^{3}$ ).

\section{Conclusions}

The emission of different pollutants during hair and nail treatments, cooking and preparing meals, but also printing and plotting significantly alter the chemical composition of the respirabile $\left(\mathrm{PM}_{4}\right)$ as well as the total PM (TSP) inside those facilities in relation to 
the chemical composition of these PM fractions in atmospheric air.

The observed changes appears by both: an increase in the concentration of PM-bound components (especially carbon compounds and water-soluble ions) as well as their mass share in PM. Nevertheless, the migration of PM and especially its respirable fraction from the outside, is an important and essential source of PM in the indoor air of all tested facilities.

The work has been financed by National Science Centre in Poland under the project no. UMO2013/09/N/ST10/04224

\section{References}

1. Cosmetic Ingredient Review, Int J Tox. 27(4):1 (2008)

2. P. Pant, R.M. Harrison. Atmos. Environ. 77:78-97 (2013)

3. W. Rogula-Kozłowska, K. Klejnowski, P. Rogula-Kopiec, L. Ośródka, E. Krajny, B. Błaszczak, B. Mathews, Air Qual Atmos Hlth. 7:41-58 (2014)

4. J.S. Pastuszka, W. Rogula-Kozłowska, E. Zajusz-Zubek Environ, Monit Assess. 168 (1-4):613-27 (2010)

5. W. Rogula-Kozłowska. Bull Environ Contam Toxicol. 93:493-502 (2014)

6. G. Gennaro, L. Gennaro, A. Mazzone, F. Porcelli, M. Tutino Atmos Environ. 83:119$126(2014)$

7. A. Tsigonia, A. Lagoudi, S. Chandrinou, A. Linos, N. Evlogias, E.C. Alexopoulos, Int. J. Environ. Res. Public Health. 7:314-324 (2010)

8. V.M. Pak, Powers M, Liu J., Workplace Health \& Safety 61(12):522-529 (2013)

9. L.M. Castro, C.A. Pio, R.M. Harrison, D.J.T. Smith, Atmos. Environ. 33(17):27712781 (1999)

10. P. Arezes, J.S. Baptista, M.P. Barroso, P. Carneiro, P. Cordeiro, N.N. Costa, R.B. Melo RB, Sergio A. MiguelA, G. Perestrelo, Occupational Safety and Hygiene II. Taylor \& Francis Group (2014)

11. P. Pant, R.M. Harrison, Atmos. Environ. 77:78-97 (2013)

12. R.W. Atkinson, A. Analitis, E. Samoli, G.W. Fuller, D.C. Green, I.S. Mudway, H.R. Anderson, F.J. Kelly, J Exp Sci Environ Epidemiol. 26:125-132 (2016)

13. W. Rogula-Kozłowska, Environ Protec Eng. 41(2):15-29 (2015)

14. P. Rogula-Kopiec, J.S. Pastuszka, W. Rogula-Kozłowska, W. Mucha; Młodzi Naukowcy; 7 (2017)

15. P. Rogula-Kopiec, J.S. Pastuszka, W. Rogula-Kozłowska, W. Mucha, ASEE17, (2017)

16. W. Rogula-Kozłowska, B. Kozielska, G. Majewski, P. Rogula-Kopiec, W. Mucha, K. Kociszewska, J. Environ. Sci. (2017),

17. J.H. Seinfeld, S.N. Pandis, Atmospheric chemistry and physics: from air pollution to climate change. John Wiley \& Sons (2006)

18. M. Sharma, S. Kishore, S. N. Tripathi, S. N. Behera, J Atmos Chem. 58:1-17(2007) 